\title{
Adjuvant radiotherapy versus observation alone, after radical prostatectomy in high risk prostate cancer
}

\author{
Andrea Petruzziello ${ }^{1 *}$, Massakazu Kato², Lais Cristine Nienkotter ${ }^{3}$, Luis Felipe Matiusso de Souza³ \\ Luiz Antônio Negrão Dias ${ }^{4}$, Murilo Luz ${ }^{4}$ \\ ${ }^{1}$ General Surgeon - Surgical Oncology Resident at Hospital Erasto Gaertner, Curitiba, PR, Brazil \\ ${ }^{2}$ Surgical Oncologist - Head of Abdominal Surgery Department at Hospital Erasto Gaertner, Curitiba, PR, Brazil \\ ${ }^{3}$ Medical Student - Internship at Hospital Erasto Gaertner, Curitiba, PR, Brazil \\ ${ }^{4}$ Surgical Oncologist - Surgical Oncologist at Abdominal Surgery Department at Hospital Erasto Gaertner, Curitiba, PR, Brazil
}

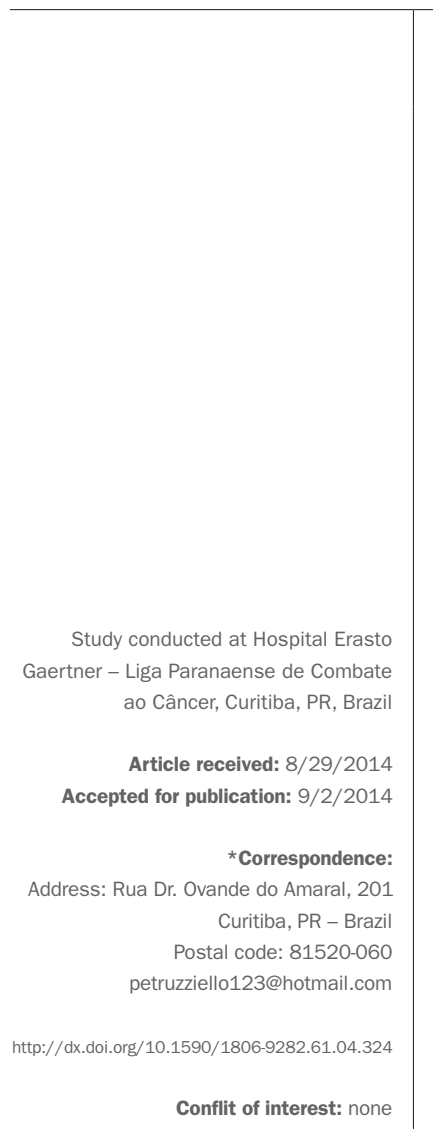

\section{SUMmARY}

Objectives: the authors compared biochemical and clinical outcomes of patients with resected high-risk prostate cancer, managed with adjuvant radiotherapy or observation alone.

Methods: patients treated with radical prostatectomy (RP) between January 1995 and December 2005 at the authors' department were evaluated. Patients with pT3, with or without positive surgical margins (PSM), were included for analysis. Demographic, clinical, pathologic and follow-up data were recorded. Comparison was made between adjuvant radiotherapy group (AR) and observation alone group (OA). Primary end-point was biochemical progression-free survival.

Results: out of 739 patients treated with RP, 49 presented with PT3 with or without PSM. 39 received adjuvant radiotherapy and 10 were observed. Median follow-up was 6.2 years for AR and 7.3 years for OA. Biochemical progression occurred in $12.8 \%$, in AR, and $70 \%$, in OA ( $\mathrm{p}=0.0008)$. Five-year biochemical progression-free survival was $87.1 \%$ in AR and $30 \%$ in OA (HR 0.12, 95\% CI 0.03 $0.48-\mathrm{p}<0.0001)$. Rescue androgen deprivation therapy was needed in $2.6 \%$, in $\mathrm{AR}$, and $30 \%$, in $\mathrm{OA}(\mathrm{p}=0.023)$.

Conclusions: adjuvant radiotherapy after radical prostatectomy in high-risk prostate cancer provided better biochemical outcomes. Whether this translates into better clinical progression, it is still unknown.

Keywords: prostatic neoplasms, prostatectomy, adjuvant radiotherapy, recurrence.

\section{INTRODUCTION}

Radical prostatectomy (RP) is commonly accepted as a treatment with excellent oncologic results in cancer confined to the prostate. ${ }^{1,2}$ However, positive surgical margins (PSM), as well pT3 lesion and extra-capsular extension, have been recognized as predictors of biochemical and local recurrence. ${ }^{3,4}$

Three randomized clinical trials have addressed the role of adjuvant radiotherapy (AR) following RP for highrisk prostate cancer (PC). ${ }^{5,7}$ These trials showed biochemical and local relapse-free survival advantages, but failed to demonstrate long-term metastasis-free and overall survival superiority. Thompson et al. ${ }^{8}$ published a long-term follow-up of their previous randomized trial. This is the only known report suggesting that AR provides superior metastasis-free survival and overall survival.
This study reports a retrospective analysis of the author's experience in the adjuvant treatment of resected high-risk prostate cancer. The initial assumption is that AR can offer better oncologic outcomes compared to observation alone $(\mathrm{OA})$.

\section{Methods}

After the approval of the Local Research Ethics Committee, all medical records of patients who underwent radical prostatectomy for prostate cancer between January 1995 and December 2005 at our Department were evaluated. Patients with 2010-AJCC (American Joint Commitee on Cancer) PT3 stage, with or without positive surgical margins at definitive pathologic analysis, were selected for possible analysis. Patients that received neo- 
adjuvant treatment, post-operative androgen deprivation therapy (ADT) concomitant to radiotherapy, positive lymph node at pathology analysis, previous prostate surgical intervention, other concomitant malignancy, or insufficient data on medical chart, were excluded from the final analysis.

For each patient, the following clinical variables were reviewed: age, initial prostate-specific antigen (PSA), Gleason score at biopsy and ASA (American Society of Anesthesiologist) score. Specimen data evaluated were: pathology AJCC clinical stage, extra-capsular invasion and positive surgical margins. PSA detection after surgery was recorded.

Follow-up outcomes included the indication of adjuvant radiotherapy or observation alone, presence of biochemical recurrence (considered as $0.2 \mathrm{ng} / \mathrm{dL}$ PSA level above nadir), diagnosis of bone metastasis (indicated by bone radiography, computed tomography or bone scan), need for rescue androgen deprivation therapy and rescue radiotherapy, and follow-up length.

Death was considered related to prostate cancer if secondary to local complications (pelvic) or metastatic disease.

Patients were divided into 2 groups for comparison purposes: the adjuvant radiotherapy group, and the observation alone group.

Primary end-point analysis was biochemical progression-free survival. Secondary end-points were need for rescue androgen deprivation therapy, metastasis-free survival and overall survival.

Statistical analysis was carried out using SPSS v.17, EPI info 3.5 software, applying Chi-Square, Fisher's exact test and Student's t-test, when necessary. Biochemical relapsefree survival was calculated using Kaplan-Meier method with log-rank test. The p-values were two sided at the significance level of $<0.05$.

\section{Results}

\section{Demographics}

From January 1995 to December 2005, 739 patients were treated for PC at Erasto Gaertner Hospital with RP. Forty-nine presented with $\mathrm{pT} 3$ with or without PSM at definitive pathologic analysis.

After verifying that no exclusion criteria could be applied, those 49 patients were included for analysis. Thirty-nine (79.6\%) received AR, and 10 (20.4\%) were observed without initial intervention.

Table 1 shows baseline demographic characteristics. Mean age at diagnosis, ASA score, preoperative PSA and Gleason score at biopsy were similar among groups.
Table 2 demonstrates the final pathology report of the specimen. Pathologic clinical stage and extra-capsular invasion were similar. PSM were more common in the AR group (89.7\%) than in the OA group (50\%) - $\mathrm{p}=0.0116$.

\begin{tabular}{|c|c|c|c|}
\hline & AR & Observation & p-value \\
\hline $\mathbf{n}$ & 39 & 10 & \\
\hline \multicolumn{4}{|l|}{ Age } \\
\hline Mean (years) & 65 & 65 & 0.99 \\
\hline \multicolumn{4}{|l|}{ ASA score } \\
\hline I and II & 36 & 10 & 0.99 \\
\hline III & 3 & 0 & \\
\hline \multicolumn{4}{|c|}{ Preoperative PSA } \\
\hline Mean & 13.2 & 16.8 & 0.47 \\
\hline$<10$ & 21 & 3 & 0.29 \\
\hline$\geq 10$ & 18 & 7 & \\
\hline \multicolumn{4}{|l|}{ Gleason score } \\
\hline Mean & 6 & 6 & 0.99 \\
\hline
\end{tabular}

TABLE 2 Specimen pathology report.

\begin{tabular}{llll} 
& AR & Observation & p-value \\
\hline $\mathbf{n}$ & $\mathbf{3 9}$ & $\mathbf{1 0}$ & \\
\hline Pathologic stage & & & \\
\hline PT3a & 34 & 8 & 0.62 \\
\hline PT3b & 5 & 2 & \\
\hline Extra-capsular invasion & & & 0.076 \\
\hline Yes & 14 & 7 & \\
\hline No & 25 & 3 & 0.0116 \\
\hline Positive surgical margins & & & \\
\hline Yes & 35 & 5 & \\
\hline No & 4 & 5 & \\
\hline AR: adjuvant radiotherapy. & & &
\end{tabular}

Follow-up

- Median follow-up was 6.2 years for AR and 7.3 years for OA ( $\mathrm{p}=0.25)$. Results are summarized in Table 3.

- Post-operative PSA was undetectable in $64.1 \%$ of AR and in $60 \%$ of OA ( $\mathrm{p}=0.99)$.

- Biochemical progression, our primary end-point, occurred significantly less in patients treated with AR, $12.8 \%$, against $70 \%$ in $\mathrm{OA}(\mathrm{p}=0.0008)$. Estimated KaplanMeier biochemical progression-free survival in 5 years (Figure 1) was significantly higher for AR than for OA: 87.1 versus $30 \%$ (HR $0.12,95 \%$ CI $0.03-0.48$ ), $\mathrm{p}<0.0001$.

- AR group needed rescue androgen-deprivation therapy (ADT) in $2.6 \%$ of cases, comparing to $30 \%$ in OA group $(\mathrm{p}=0.023)$. 
- Bone metastasis occurred in only one patient in each group ( $\mathrm{p}=0.37$ ). No cancer-specific death occurred during the follow-up period.

\section{TABLE 3 Follow-up.}

\begin{tabular}{llll} 
& AR & Observation & p-value \\
\hline $\mathbf{n}$ & $\mathbf{3 9}$ & $\mathbf{1 0}$ & \\
\hline Post-operative PSA & & & \\
\hline Detectable & 14 & 4 & 0.99 \\
\hline Undetectable & 25 & 6 & \\
\hline Biochemical progression & & & 0.0008 \\
\hline Yes & 5 & 7 & \\
\hline No & 34 & 3 & 0.023 \\
\hline Rescue ADT & & & \\
\hline Yes & 1 & 3 & \\
\hline No & 38 & 7 & \\
\hline
\end{tabular}

ADT: androgen deprivation therapy; AR: adjuvant radiotherapy.

\section{Discussion}

These results show a significant longer biochemical relapse-free survival and a significant lower need of rescue ADT, in patients treated with AR for high-risk resected PC.

Bone metastasis was a rare event, and the authors did not register mortality directly related to PC.

Limitations of this analysis include its retrospective nature and heterogeneity in some characteristics between groups.
Similar results have been reported by several retrospective, non-randomized studies, ${ }^{9,10}$ all sharing similar bias common to such retrospective analyses.

In 2005, the European Organisation for Research and Treatment of Cancer (EORTC) trial $22911^{5}$ was the first large, multicentric, randomized trial, trying to evaluate the role of AR in high-risk resected PC. This study found better biochemical relapse and clinical local relapse-free survival, but could not assess metastasis-free survival and overall survival due to the short follow-up.

Thompson et al. ${ }^{6}$ published the second large randomized trial assessing the same question. This study had a more audacious primary end-point, metastasis-free survival. It failed in reaching this end-point, with a tendency to better distant failure outcomes with AR, but without reaching statistical significance $(\mathrm{p}=0.06)$. Overall survival advantage could not be proved, at a mean followup of 10.9 years $(\mathrm{p}=0.16)$. Similar to EORTC 22911 results, AR showed significant better biochemical relapse and local relapse-free survival.

In 2009, Thompson et al. ${ }^{8}$ published a longer followup of their previous reported trial. With a median followup of 12.7 years, they could demonstrate a significant better metastasis-free survival (HR 0.71 in favor of AR) and a significant better overall survival (15.2 versus 13.3 years, HR 0.72 in favor of AR). To date, this is the only report of metastasis-free and overall survival advantage of AR.

The ARO96-02/AUO AP09/95 trial, ${ }^{7}$ published in 2009, the last randomized trial published comparing AR

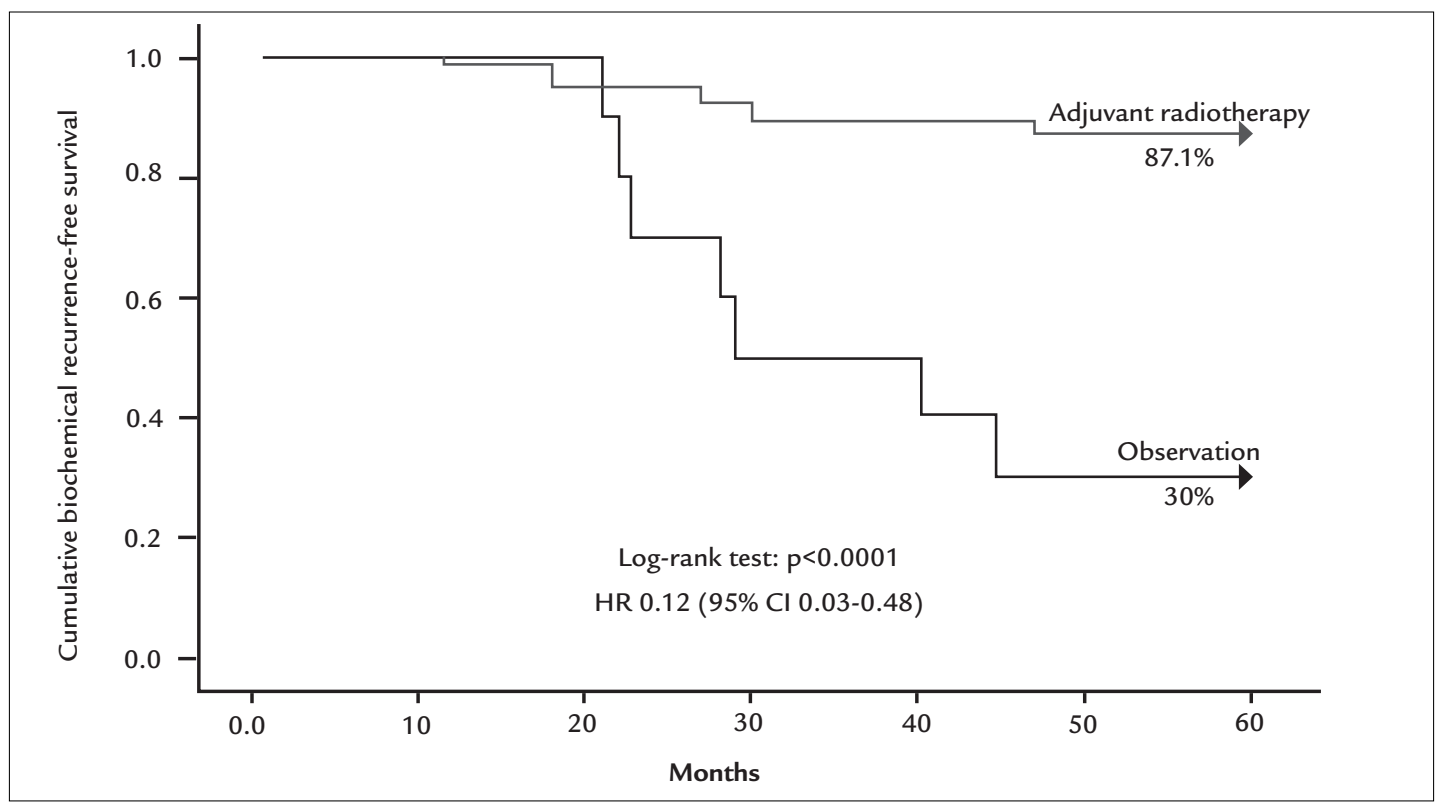

FIGURE 1 Cumulative biochemical recurrence-free survival in 5 years.

Image courtesy of author. 
to $\mathrm{OA}$, analyzed separately patients with postoperative undetectable PSA. Even in these possible lower-risk patients, they could demonstrate better biochemical relapsefree survival. The trial could not show additional clinical benefits.

A common criticism to these randomized studies is the small radiation dose, generally from 60 to $64 \mathrm{~Gy}$, and a high proportion of patients treated with $2 \mathrm{D}$ technique. Such protocol was the standard radiotherapy treatment when many of the included patients were randomized. Today, common treatment is 66 to $80 \mathrm{~Gy}$, delivered with 3D or intensity-modulated radiation therapy (IMRT) planning. ${ }^{9,11}$ However, this bias should probably not influence negatively data interpretation. Some suggest that the clinical results of these trials are underestimated by the worse radiotherapy technique available at the time, and that new trials with modern protocols could probably lead to even better results.

Differently from 2005, when the last patients selected for this analysis were included, AR is now a well-accepted therapy, and is offered routinely to our patients when presenting with a high-risk resected PC.

During the evaluated period, 1995-2005, AR was not a standard protocol at Erasto Gaertner Hospital. At the time, we did not have the results of the previous described trials. ${ }^{5-8}$

We could not identify selection criteria to AR or OA adopted in the patients, other than personal preference of the attending oncologist. This can generate a selection bias, not uncommon in such retrospective studies.

Nevertheless, we emphasize that if the two analyzed groups were different, AR group can be considered a higher risk group, due to the significant higher proportion of PSM. Even with predictable worse outcomes in this group, AR could actually overcome the worst prognosis, and show a significant longer biochemical relapse-free survival.

Another important result is the significant less dependency of rescue ADT in AR group. ADT use is a frequent worry for the oncologist, due to the expiration date of its benefits and the known short and long-term side effects.

\section{Conclusion}

In agreement to growing and already strong evidence in favor to AR after resected high-risk PC, the authors showed significant better outcomes with adjuvant radiotherapy.

Although proving better metastasis-free and overall survival advantages in PC is difficult, it was already suggested in previous randomized trials that the biochemical advantage of AR also translates into better clinical outcomes.

In the author's opinion, AR provided better treatment in these selected patients, it is now the first choice when facing high-risk resected PC, and should always be offered as an option to the patient.

\section{Resumo}

Radioterapia adjuvante versus vigilância após prostatectomia radical em câncer de próstata de alto risco

Objetivo: comparar resultados clínicos e bioquímicos de pacientes com câncer de próstata de alto risco submetidos à prostatectomia radical, tratados com radioterapia adjuvante (RA) ou vigilância.

Métodos: foram avaliados os pacientes tratados com prostatectomia radical, entre janeiro de 1995 e dezembro de 2005. Pacientes que apresentaram pT3, com ou sem margens cirúrgicas positivas, foram incluídos para análise. Foram registrados dados demográficos, clínicos, patológicos e de seguimento. Foram comparados os resultados entre o grupo que recebeu RA e o grupo em vigilância. O desfecho principal avaliado foi a sobrevida livre de progressão bioquímica.

Resultados: entre os 739 pacientes tratados com prostatectomia radical, 49 apresentaram tumores pT3, com ou sem margens cirúrgicas positivas. Trinta e nove receberam RA e 10 foram submetidos à vigilância. $\mathrm{O}$ seguimento médio foi de 6,2 anos para a RA e de 7,3 anos para a vigilância. Houve progressão bioquímica em $12,8 \%$ dos pacientes no grupo RA e em $70 \%$, no grupo da vigilância $(\mathrm{p}=0,0008)$. A sobrevida livre de progressão bioquímica em 5 anos foi de $87,1 \%$ na RA e $30 \%$ na vigilância (HR 0,12, IC95\% 0,03-0,48 - $\mathrm{p}<0,0001)$. Terapia hormonal de resgate foi necessária em 2,6\% dos pacientes na RA e em 30\% na vigilância $(\mathrm{p}=0,023)$.

Conclusões: a radioterapia adjuvante após prostatectomia radical em pacientes com câncer de próstata de alto risco ofereceu melhores resultados bioquímicos. Ainda não está claro se isso se traduz em uma evolução clínica melhor.

Palavras-chave: prostatectomia, radioterapia adjuvante, neoplasias da próstata, recidiva.

\section{References}

1. Roehl KA, Han M, Ramos CG, Antenor JA, Catalona WJ. Cancer progression and survival rates following anatomical radical retropubic prostatectomy in 3,478 consecutive patients: long-term results. J Urol. 2004; 172(3):910-14

2. Chunk FK, Graefen M, Zacharias M, Haese A, Steuber T, Schlomm T, et al. Anatomic radical retropubic prostatectomy long-term recurrence free-survival rates for localized prostate cancer. World J Urol. 2006; 24(3):273-80.

3. Swindle P, Eastham JA, Ohori M, Kattan MW, Wheeler T, Maru N, et al. Do margins matter? The prognostic significance of positive surgical margins in radical prostatectomy specimens. J Urol. 2005; 174(3):903-7. 
4. Billis A, Meirelles LL, Freitas LLL, Magna LA, Reis LO, Ferreira U. Influence of focal and diffuse extraprostatic extension and positive surgical margins on biochemical progression following radical prostatectomy. Int Braz J Urol. 2012; 38(2):175-84.

5. Bolla M, van Poppel H, Collette L, van Cangh P, Vekemans K, Pozzo L, et al. Postoperative radiotherapy after radical prostatectomy: a randomized controlled trial (EORTC trial 22911). Lancet. 2005; 366(9485):572-8.

6. Thompson IM Jr, Tangen CM, Paradelo J, Lucia MS, Miller G, Troyer D, et al. Adjuvant radiotherapy for pathologically advanced prostate cancer: A randomized clinical trial. JAMA. 2006; 296(19):2329-35.

7. Wiegel T, Bottke D, Steiner U, Siegmann A, Golz R, Storkel S, et al. Phase III postoperative adjuvant radiotherapy after radical prostatectomy compared with radical prostatectomy alone in $\mathrm{PT} 3$ Prostate cancer with postoperative undetectable prostate-specific antigen: ARO 96-02/AUO AP 09/05. J Clin Oncol. 2009; 27(18):2924-30.
8. Tompson IM Jr, Tangen CM, Paradelo J, Lucia MS, Miller G, Troyer D, et al. Adjuvant radiotherapy for pathological T3N0M0 prostate cancer significantly reduces risk of metastases and improves survival: long-term followup of a randomized clinical trial. J Urol. 2009; 181(3):956-62

9. Ost P, Fonteyne V, Villeirs G, Lumen N, Oosterlinck W, De Meerleer G. Adjuvant high-dose intensity-modulated radiotherapy after radical prostatectomy for prostate cancer: clinical results in 104 patients. Eur Urol. 2009; 56(4):669-75.

10. Brodak M, Kosina J, Holub L, Louda M, Odrazka K, Dolezel M, et al. Radical prostatectomy in high-grade prostate cancer, salvage and adjuvant radiotherapy. Urol Int. 2011; 86(2):146-51.

11. Zelefsky MJ, Levin EJ, Hunt M, Yamada Y, Shippy AM, Jackson A, et al. Incidence of late rectal and urinary toxicities after three-dimensional conformal radiotherapy for localized prostate cancer. Int J Radiation Oncol Biol Phys. 2008; 70(4):1124-9. 